\title{
De Statuur van Jan van Riebeeck en de Betekenis van de Volksplanting.
}

HET is Van Riebeeck gegaan als vele groten van ons geslacht; hij heeft ervaren, dat .... deucht met ondeucht geloont wert.

In 1927 heeft wijlen de Leidse professor Knappert een aantal, aan Joan van Riebeeck's Dagverhaal ontleende mededelingen in dezer voege samengevat: ,het is van Riebeeck gegaan als vele groten van ons geslach1; hij heeft ervaren, dat . . . deucht met ondeucht geloont wert." Noch in Amsterdam noch in Batavia hadden de bureaucraten veel met de Kaap op. Het goud uit de mijnen vloeide niet toe, de korenbouw bracht niet genoeg op, maar klachten over den commandeur, zijn bewind en de Kolonie waren er niet, dan dat de vrije landbouwers zo lui waren (door de toenemende slavernij). En toch nimmer een goed woord. Zo

\section{Deur A. A. VAN SCHELVEN.}

ging Van Riebeeck verlangen zijn post neer te leggen om „so veelderley passerende ongenoegsaeme en onvoldoenlijcke humeuren niet meer subiect te sijn." Men kan het niet ieder naar den zin maken, wat men goeds doet word vergeten, wat kwaads vergroot en alleen aangerekend. Hij vroeg zijn verlossing en kreeg ze 21 Aug. 1660 zonder een woord van dank ..., sal mette eerste gelegentheijt nae Batavia hebben te vertrecken om aldaer wijders ten dienste van de Compagnie te worden geëmployeert." Dat was alles! . . Toen wees men in Batavia Zacharias Wagenaar aan; na een zware reis kwamen hij en zijn vrouw, ,reeds 
rijckelijck met jaren versiert" per jacht De Anjelier 2 April 1662 in de Tafelbaai ten anker. In een brief van Heren XVII aan hem krijgt Van Riebeeck nog eens een vinnigheid: „In soodanigen manieren (optimistische rapporten over den graanbouw) van doen houden wij ons niet ten besten gesticht; en verstaan, dat men ons na desen niet als van waerachtighe en trouwe rapporten sal hebben te dienen." Was het niet natuurlijk geweest, dat de commandeur, die zijne stichting lief had gekregen, er over geschreven had met warmte en opdat hij er belangstelling voor wekken mocht?

In den avond van 7 Mei 1662 voeren hij en de zijnen op het schip Mars de baai uit met een laatsten blik op het fort en daarnaast het dorp van lage, kleine huisjes, het begin van de metropool van Hollands SuidAfrika. De laatste bladzijde van het Dagverhaal, door Wagenaar geschreven, vermeldt het vertrek zonder één woord daaraan toe te voegen. Het laatste woord daarop is: „Den 8sten zijn dese nacht met de lichte maen de schepen Mars en Amstelant zeijl gegaen naer Batavia .... Tegen den avond is de huysfrou van den vrij-herbergier Hendrick van Zeurwaerden comen te geleggen van een jongen soon ende een dito dochter." De luim der historie heeft gewild, dat dit bericht van rijkelijken huwelijkszegen in de Kaapse taveerne de laatste woorden zouden zijn van een journaal dat, onder onze beroemdste koloniale bescheiden, tot onze glorierijkste herinneringen behoren zou. In deze ondank, in deze nuchterheid is iets zeer droevigs; wij kunnen ons slechts tot onze vertroosting te binnen brengen, dat de namen der Heren XVII ao 1662 vergeten zijn en dat de faam van Van Riebeeck over de ganse aarde is uitgegaan.

Is het in verband met dezen gang van zaken vooral mijn plicht na te gaan wat de zo ondankbaar behandelde man gevoeld en geleden heeft? Ik meen van niet. Want niet de persoonlijke ondervindingen van een individuele mens zijn het, waarop een uitgave als deze haar aandacht vestigt. De vraag naar hetgeen het Suid-Afrikaanse volk in de betrokken figuur uit zijn geschiedenis ontvangen heeft staat erbij in het middelpunt. En de stamverwant uit het oude Europa, die aan de tekening van dit beeld meewerkt, heeft zich bij dezen algemeenen opzet van he1 werk aan te sluiten.

Menselijkerwijs gesproken is het nogal toevallig geweest, dat Van Riebeeck ten opzichte van Suid-Afrika de plaats heet ingenomen, waarvan wij de dankbare herinnering bewaren. Meer dan eens is hij eerst op den voorgrond komen te staan doordat een aanvankelijk plan, waarin hem geen rol, of althans geen belangrijke rol was toegedacht, wijziging had ondergaan. De Heren XVII, die van Amsterdam uit de Verenigde Oost- 
Indische Companie bestuurden, hadden - om een voorbeeld te noemenaanvankelijk besloten, dat een van de schipbreukelingen van de Haerlem, die gedurende een paar maanden ter plaatse opzettelijk de mogelijkheid om aan de Kaap de Goede Hoop een ,zeeherberg" van blijvende aard in het leven te roepen hadden kunnen nagaan, dat een zekere Matthijs Proot bij het organiseren van een permanente verversingspost voor de scheepsbemanningen, die voortdurend maar door de scheurbuik werden gedecimeerd, de leiding zou hebben. Maar toen de Dromedaris, de Reiger en de Hoop, die aan dit plan begin van uitvoering moesten geven, bij Texel het zeegat uitliepen en op 30 December 1651 onder de Engelse kust--omdat de Dromedaris last gaf bij de navigatie--hun eerste gecombineerde scheepsraad hielden, bleek Proot ervoor te hebben gepast aan het verlangen der meesters van het Oost-Indische huis gevolg te geven en zat Van Riebeeck de vergadering voor. En desgelijks toen men na een voorspoedige reis aan de voet van de Tafelberg geland was. Aanvankelijk zou de oudchirurgijn, die Culemborg onder het Zuiderkruis beroemd heeft gemaakt, na een jaar weer verder getrokken zijn en dus uitsluitend de allereerste spade voor het nieuwe bouwwerk in de grond hebben gestoken. Dat het tenslotte niet minder dan tien jaar-van 6 April 1652 tot 7 Mei 1662-geduurd heeft eer hij zijn post daar aan een opvolger heeft overgedaan, gebeurde dus ook al met afwijking van het plan, dat men in deze aanvankelijk voor het beste had aangezien.

Dit was een belangrijker factor dan hij ons oppervlakkig gezien voorkomt te wezen. Want Van Riebeeck in plaats van Proot, en tien jaar Van Riebeeck in plaats van deze leidsman iets meer dan tien maanden: dat was niet alleen een andere man dan de oorspronkelijk aangewezene, dock ook een andere manier.

Ik neem graag aan, dat Proot een eersteklas ambtenaar van Jan Kompanie is geweest. „Sekuur en zakelijk” beweert en bewijst Godée Molsbeergen, dat hij zich bij de vervulling der hem gegeven opdrachten getoond heeft. Welnu, welke maatschappij zou zich niet gelukkig achten wanneer zij over medewerkers van die aard beschikken kon! Toch, verder dan door de moeiten van hen, die met een priesterlijken geest bezield zijn en hun krachten aan de instandhouding van de gestelde regels wijden, komt onze menselijke sameleving door de inspanning der mannen, die van een profetische geest bezeten zijn; der bezielers van de traditie met de geest, waardoor zij in het leven werd geroepen. M.a.w. gezegd: dergenen, die uit de potaard zijn gevormd, waaruit ook Jan van Riebeeck was gemaakt.

Om de scherpe tegenstelling, die tussen hem en zijn opvolger Zacharias Wagenaar heeft bestaan, te doen gevoelen heeft de Suid-Afri- 
kaanse historicus McCall Theal een kwalificatie, die een Engelse scheepskaptein--dus een man, die van zijn hart geen moordkuil pleegt te maken en graag een ziltig woord plaatst-eens van hem gaf, gegeneraliseerd tot "het oordeel zijner tijdgenoten" over hem en zoodoende beweerd, dat men hem "the little rogue," de kleme boef, placht te noemen. Maar daarmee heeft hij hem toch werkelijk niet tot zijn recht laten komen. Wie, die energiek is en nu en dan ingrijpende maatregelen meent te moeten nemen wekt niet vanzelfsprekend bij dezen en genen ontevredenheid? Maar dit wil toch niet zeggen, dat zijn hand tegen allen is en de hand van allen tegen hem en dat nog wel voortdurend.

Met dat al: èn in Amsterdam èn in Batavia heeft men vrij wat grieven tegen hem gekoesterd.

De Heren in het vaderland vonden, dat hetgeen hij ondernam, in aanmerking genomen de geringe baten, die het opleverde, te veel geld kostte. Kooplieden, als zij waren, hadden die vanzelfsprekend vooral belangstelling voor de vraag, of de inspanning, die de Compagnie zich getroostte, wel genoeg finantiële resultaten afwierp. Anders echter de klachten, die men op Java, waar de Gouverneur-generaal en de Raad van Indie zetelden, over zijn optreden uitte. De verhoudingen, die men daar aantrof, de wonderen van de oosterse wereld, waardoor men daar telkens opnieuw geimponeerd werd, maakten, dat men er tenminste wel eenig begrip kreeg van de omstandigheden, temidden waarvan Van Riebeeck koers moest zoeken. Maar geheel vervallen deden de beschuldigingen tegen de manier, waarop hij zijn taak vervulde toch niet. Een optimist zonder weerga werd hii er blijkbaar gevonden. Tenminste Van Goens, de Gouverneur-generaal van het toenmalige Tropische Nederland, die het door Jan Pietersz. Coen van de Molukken naar West-Java verlegde middelpunt daarvan nog weer verder naar het Westen wilde verleggen en Ceylon tot de spil ervan maken; Van Goens, die ook niet bang voor het ontwerpen van grootscheepse plannen was, legde Van Riebeeck ten laste een man van "winderige concepten" te wezen.

Onwillekeurig dringt zich aan wie van deze beschuldigingen kennis neemt de vraag op, waaraan de Toewan Besar, de grote Heer, gedacht zal hebben.

Stellig niet aan de wijze, waarop Van Riebeeck getracht heeft zijn nederzetting aan de Kaap staatkundig te organiseren. Te dien aanzien heeft de nieuwe functionaris zich de zaak niet moeilijk gemaakt. Toen hij, een kleine drie weken nadat de Dromedaris haar anker in de Tafelbaai had laten vallen, dat schip voor goed tegen een woning aan de wal verwisselde handelde hij zoals de mannen van de zee het plegen te doen. In de geest, waarin het leven aan boord geregeld was, werd het op het 
droge voortgezet. Al naar de omstandigheden het wenselijk maakten werd de scheepsraad, die gedurende de reis over zeeën en oceanen de leiding over de mensen en de schepen van een eskader of een vloot gehad had, met gelegenheidsdeelnemers aangevuld. Maar de grondslag van het bewind over de personen en dingen en verhoudingen bleef zoals die van huis uit altijd bij de Compagnie geweest was. De leiding was steeds bij de voornaamste in de haven, of op de wal, aanwezige handels- of scheepvaartsfiguur. En door dezen gedirigeerd maakte de (Scheeps)Raad uit wat er moest gebeuren.

Neen, op dit gebied viel Van Riebeeck zeker niet van het invoeren van wilde en gewaagde nieuwigheden te beschuldigen. In enige andere opzichten lag de grief in ieder geval veel dichter voor de hand.

Vooreerst gaf hij in dezen vat op zich door zijn bemoeiingen ten bate van kolonisering en vrijburgerschap.

Ik ken geen deel van 's mans Dagverhaal, dat zo belangrijk is als het verslag van de gebeurtenissen op 21 Februari 1657, toen de kommandeur dus in staat was geweest de toestanden aan de Kaap een kleine vijf jaar aan te zien. Welnu, daarin wordt verteld hoe aan negen mannen, die tot nog toe hun reis om de Zuid-hetzij dat zij tot de handelsbeambten, of tot de zeevarenden behoord hadden-slechts als passanten in dienst der Compagnie voor korter of langer tijd plachten te onderbreken, een blijvende woonplaats werd toegewezen, waarop zij als onafhankelijke burgers een boerenbedrijf mochten gaan uitoefenen, zij het dan dat zij de producten van hun inspanning ter beschikking van de langsvarende Compagnie-schepen zouden moeten stellen. Negen mannen kregen dit voorrecht, zeg ik, n.l. vijf man samen onder leiding van Harmen Remajenne van Ceulen, in „de lantdouwe genaemt Groenevelt," ter bevordering speciaal van den korenbouw. En vier andere gezamenlijk, onder leiding van den blootgezel Steven Jansz van Wageningen, een man, die ook „geverseert in de tabacqplanterije” was, in de gemcenschap „Den Hollantsen thuyn" bij het Ronde Bossien, om een veelszins gemengd bedrijf uit te oefenell: le zorgen voor verbouw van graan, maar ook van tabak, het kweken van allerlei aard- en tuinvruchten en het fokken van vee en gevogelte, „waer dat se maer menen voordeel aen te bejagen.”

Voor wie in de geschiedenis der 17e eeuw geen vreemdeling is zijn deze Februari-gebeurtenissen niet zo onbegrijpelijk als zij waarschijnlijk voor veel opvarenden van de toen bij den Tafelberg aanwezige schepen zijn geweest. Onwillekeurig herleeft bij zijn kennismaken met het verslag ervan de herinnering aan Jan Pietersz. Coen's beroemd Vertooch van 1623 in zijn gedachten; aan de memorie m.a.w., waarin de stichter van het Nederlands-Indische eilandenrijk om den evenaar al een mensenleeftijd vroeger de leus heeft aangeheven, die Nederland helaas te veel ver- 
waarloosd heeft: geen compagnie van handelskantoren slechts hebben we in de tropen nodig, maar een gemeenebest van bevriende volkeren. Al is het dat Van Riebeeck waarschijnlijk meer dan onder invloed van den genialen zoon van Hoorn onder dien van Joan Maetsuyker gehandeld heeft. Als gouverneur van Ceylon in 1645 en vervolgens, en als vertegenwoordiger van de generatie, waartoe de Columborger ook zelf behoord heeft, dezen èn geographisch èn chronologisch èn in levensvisie nader staand, heeft deze opvolger van Coen de zeer grote mate van handelsvrijheid, die de ,grand old man" den vrijburgers in zijn gedroomd rijk had willen toestaan wat ingeperkt. En op dien weg zien wij den stichter van Zuid-Afrika niet naar Coen terug, integendeel nog wat verder van dezen af gaan staan. In allen gevalle: met den allergrootsten en Maetsuyker zien wij hem in dit opzicht een triumviraat vormen. Niet als par inter pares, maar dan toch wel als een goede tweede. Stellig was de gedachte van het vertooch "na ons gevoelen can de plaetse sonder aenplantinge van collonien voor de vereenichde Nederlanden niet gehouden worden," toen Van Riebeeck aan het woord kwam, lang niet zoo impopulair meer als in 1623. Maar onbestreden was zij anderzijds in zijn dagen toch ook nog volstrekt niet. Alle landgenoten, die het geduld niet hadden om een rijkeren en blijvender oogst van hun inspanning te wachten, dan de dag van vandaag hun zou kunnen verschaffen, bleven haar tegenstanders. Voor Van Riebeeck was dit echter geen reden om zijn ideaal en de pogingen om het te verwerkelijken op te geven. Met een: er is hier nog wel ruimte voor een duizend-tal gezinnen, maakte hij er rechtstreeks propaganda voor. Langs verschillende indirekte wegen deze reclame voor zijn lievelingsgedachte nog trachtend te steunen. Van 1654 af wil hij de 6 April de dag van zijn aankomst aan de Stormkaap, jaarlijks als gedenkdag gevierd zien: blijkbaar hopend door op die manier de overtuiging post te doen vatten, dat die datum in het vroege voorjaar sedert 1652 een scharnier in de geschiedenis van Afrika's Zuiden was. Als hij in den loop van 1656 eens een rondrit in de omgeving van het fort der Compagnie besluit te maken ter controle van de verschillende aanplantingen, waartoe hij opdracht had gegeven, neemt hij de Nederlandse vrouwen uit de buurt in zijn wagen mee! Alleen ter harer recreatie, zoals hij in zijn Dagverhaal beweert? Ik verdenk er hem sterk van, dat ook de wens om zodoende de publieke opinie in hun kring te bewerken, er een rol bij gespeeld heeft: wij zijn bezig een grootse onderneming uit te voeren. En lest best: tot op een afstand van wel drie honderd kilometer van de Kaap liet hij verscheidene onderzoekingstochten van zijn nederzetting uitzwermen, teneinde zich over verder mogelijkheden voor de jonge kolonie een voorstelling te kunnen maken. De Portugeezen, die vóór de Nederlanders aan de Tafelbaai geweest zijn, hadden dat nooit 
gedaan. En evenmin de scheepsbemanningen van de galjoten en fluitschepen der Compagnie, die vóór hem hun anker in de "Zeeherberg" hadden uitgeworpen: het volk van Pieter Both in 1609 en Isaäc Lemaite in 1611 bijvoorbeeld en de schipbreukelingen van de Haerlem, die zich maanden achtereen noodgedwongen daar hebben moeten ophouden. Maar hij, Van Riebeeck, achtte de inspanning en de kosten, die deze reizen met zich meebrachten, niet nutteloos op het spel gezet. Al moesten dan de dividenden tijdelijk kleiner worden.

Voor de Heren in Patria raakte op den duur zodoende echter de aardigheid gaandeweg meer van zijn optreden af. Vooral toen de in de genoemde ondernemingen gestoken gelden nu en dan verloren bleken, konden die de geestdrift niet meer opbrengen, nodig om hun vertegenwoordiger in het verre Zuiden juist te waarderen. En dientengevolge ook bij hem raakte het vuur om de bestaande toestand langer voort te zetten toen geblust. Van Riebeeck vroeg ontslag, het oordeel over zijn werk aan de geschiedenis overlatend.

Geen man of vrouw uit 1952, van wie de gedachten zich met het Zuid-Afrika van Jan van Riebeeck bezighouden, of hij of zij zal iets betreffende de oudste verhouding tusschen degenen, die zich van Nederland uit aan de Kaap hebben gevestigd en de bevolking, die daar van oudsher woonde, willen weten.

Met het uitspreken van een oordeel over de latere ontwikkeling dier verhouding heeft dit gelukkig niets te maken. Had het er wel mee van doen, dan kon wie niet tenvolle deskundig was maar het beste over deze materie zwijgen. Uitsluitend mee te delen wat er gebeurd is toen de omstandigheden zich nog zeer voordeden brengt zulk een groot risico evenwel niet mee.

Eigenlijk moet mijn verhaal al eer Van Riebeeck bij de Amsterdamse Schreierstoren het dek van de Dromedaris, die met de vertrekvlag in top lag, betreden heeft zijn begin nemen. Op het ogenblik, waarop hem door zijn Principalen in het Oost-Indisch Huis last $w$ as gegeven zijn oordeel over het rapport van Leendert Janszen en Matthijs Proot in zake de mogelijkheden, die de Kaap voor een blijvende zeetaveerne bood, te boek te stellen. Merkwaardig, dat de man, die algemeen vooor een optimist, voor min of meer een, ,hufter" wordt versleten, in dit opzicht van te voren, al zwarter keek dan de beide mannen, die kort te voren den toestand ter plaatse hadden waargenomen. Zij hielden de Boesmans en de Hottentotten, die zij ontmoet hadden, voor vrij betrouwbaar. Van Riebeeck's waardering was echter zo gunstig niet: „wilde brutale 
mensen" kwamen zij in de uitbreiding van het Compagniesgebed, die met het oog op deze reis gemaakt werd, te heeten.

Toch is hij, toen het zover was gekomen, de weinige inheemse bewoners, waarmee hij aanvankelijk slechts in aanraking kwam, vriendelijk tegemoet getreden. Eiste het zo ook niet èn de veiligheid van hem en zijn medeschepelingen èn het belang, waarvoor men hen had uitgezonden: de verkrijging van het verse vlees, dat de door scheurbuik geteisterde bemanningen der aanlopende Oost-Injevaarders weer op de been moest helpen?

Men had onverstandiger politiek kunnen voeren. Aanvankelijk was de verhouding zoals men haar maar kon wensen. Voor het koperdraad en de tabak, die men beschikbaar stelde, verwisselde menige koe van eigenaar en herkreeg menige lijder aan scorbuut zijn gezondheid. Ook al bleken er volgens het Dagverhaal eveneens niet meer te redden. De onbekende soldaten voor die opkomst en de toekomst van Zuid-Afrika; waard in deze feestdagen naast Van Riebeeck herdacht te worden, want zonder hun simpele levens, naast het zijne ingezet en in leed en moeite geleefd en afgelegd, werden er in 1952 in twee werelddelen green Van Riebeeckfeesten gevierd.

Eerst met de hiervóór beschreven koloniseringsactiviteit van de afgezant der Heren XVII is in de goede verstandhouding, die ik tekende, de klad gekomen.

Evenals dat in de Engelse kolonien, in de dagen waarin Roger Williams met de Settlers in New England in botsing kwam, het geval geweest is, deed zich naar aanleiding van het optreden der Compagnie bij de gelegenheid de vraag voor, of de zich nieuw aanmeldende bewoners van het land de grond, waarop zij zich vestigden, niet van zijn oorspronkelijke bezitters behoorden te kopen, in plaats van zich die eenvoudig toe te eigenen. De Hottentotten meenden van w'el. Een eigenaarschap sedert eeuwen gaf hun daar een onloochenbaar recht op, beweerden die. Maar de nieuwkomers wilden daar niet van weten. Zwervende, nergens voor goed gevestigde stammen als bezitters van het gehele terrein, waarover zij heen en weer trokken, te beschouwen, is hun blijkbaar niet ingevallen.

Zo ontstonden botsingen. Nauwelijks hadden de Nederlanders hun fort gebouwd, en getoond--door hun aanleggen van akkers en tuinenwat in hun bedoeling lag, of de autochtonen trachtten door het plegen van veediefstallen en vernieling van het gewas de blanke mannen uit het Noorden tot weer weggaan te bewegen. En in Mei 1659 begon de Hottentot-oorlog en daarmee een periode, die den van overzee gekomenen veel moeite heeft berokkend. 
Nog eer Van Riebeeck het Kaapland verliet om er gedurende de rest van zijn leven nooit meer heen terug te keren leidden deze conflicten echter tot een oplossing, waarmee men tot nader order heel goed genoegen kon nemen, zegt de onbevooroordeelde toeschouwer. Binnen het Compagnies gebied, dat door de drie blokhuizen, Kijck-uyt, Keert-de-Koe en Houdt-den-Bul een afgrenzing kreeg, zouden de ingeborenen voortaan geen zeggenschap meer hebben. Maar daarbuiten mochten zij hun vee weiden, waar hun dat goeddacht.

Toen Van Riebeeck waar nu zijn monument staat voet aan wal zctte, was hij, de bijna 35-jarige, vergezeld van zijn ruim tien jaar jongere vrouw, Maria de la Quellerie, een Hugenotenkind. Zegt ons dit misschien iets ten aanzien van zijn levensopvatting?

Ik kan bij de behandeling van deze stof, dunkt me, niet beter doen, dan van de voorstelling uitgaan, die C. Louis Leipoldt anno 1936 in zijn biografie van den kommandeur heeft gegeven.

De schrijver daarvan heeft zich er duidelijk zichtbaar op toegelegd het gezin van diens grootvader te Culemborg, waarin de jonge Jan achtereenvolgens tot knaap en tot jonge man is opgegroeid, voor een eiland van „ruimheid” te midden van de strikte Calvinistische kringen, die doorgaans in de Nederlandsche steden den toon aangaven in de eerste helft der 17-eeuw, een uitzonderingspositie te verlenen, en dies ook van Van Riebeeck een uitzonderingsfiguur te maken. Op deze manier: "At his grandfather's house he would also have had the opportunity to learn card games" (bldz 16). "While dancing was eschewed in the stricter Calvinistic circles, it was probably encouraged in the more broad-minded Culemborg" (blz. 16). "It is quite possible that the local schoolmaster was someone who would not have been cordially approved of by the more rigid Calvinists" ... "at Culemborg, which prided itself on its independence of thought and action" (bldz. 17) "we may charitably suppose that at Culemborg, at least, the interpretation of Bogerman's syllabus was on a more liberal scale and in a more pedagogical spirit than its author had postulated" (bldz. 20). "Neither the Commander nor his wife was a bigoted Calvinist, and it may be assumed that this ritual prayer" (sc. het door de Compagnie voor de vergaderingen harer employé's vastgestelde) "made no greater impression on them than the then common fulminations against the Arminians did on the mass of the Dutch population" (bldz. 102).

Is dit beeld aanvaardbaar?

Stellig niet. Het is dat evenmin als de vroeger wel eens te eenzijdig voorgestane mening als ware de bevolking van de Republiek der Zeven Verenigde Provinciën in de Gouden Eeuw een gemeenschap van alleen 
maar oprecht overtuigde en zich model gedragende Calvinisten geweest. Geen enkel volk en zelfs geen enkele gemeenschap van geestverwanten is-om Huizinga's gelukkige vondst hier te hulp te roepen-in geestesmerk één. Waarheidsliefde vereist omgekeerd om te dezen allerlei variaties aan te nemen. Calvinisten, Libertijnen, naar het Anabaptisme neigenden, Roomskatholieken en Piëtisten naast elkaar. En om mij nu verder uitsluitend met de Calvinisten bezig te houden: leden der bevoorrechte Kerk en aan het Calvinisme verwante sectariërs. Calvinisten van het type-Frederik III van de Palts en diens aanhangers Dathenus en Petrus Beuterich, die den wens koesterden „de calviniser le monde" en Willem de $Z$ wijger beschouwden als een uitsluitend door eerzucht voortgedreven man, die naar de omstandigheden handelde, maar niet uit godsdienstigen ijver, en andere, die hetzelfde genre als de grote Oranje vertoonden. Lieden als de Engelse Presbyterianen uit Cromwells dagen, die in één adem van een chaos, een Babel en Amsterdam gewag maakten, omdat de Regenten der laatstgenoemde stad ter wille van de voorspoed van hun stad en het land tolerantie voorstonden. En een kern van aanhangers der Calvinistische geestesbeweging naast een veel omvangrijker corona, bij wie zij niet veel meer dan een uitwendige cultuurvorm was.

En nu de vraag onder de ogen gezien waar te midden van al deze schakeringen Van Riebeeck te plaatsen.

Natuurlijk kregen wij een scheefgetrokken beeld van den man wanneer wij uit het oog verloren, dat veel van wat hij gewild en gedaan heeft niet van persoonlijken aard is geweest, maar als uitvloeisel van zijn ambtenaarspositie behoort te worden in aanmerking genomen. Als aan boord van het schip, waarop hij naar zijn bestemming op weg is gegaan, aan boord van de al meermalen vermelde Dromedaris, iedere avond na den maaltijd een gebed wordt gedaan "na de gelegenheijt des tijds," en des Zondags beurtelings een gedeelte van het Evangelie, of een verklaring van den Heidelbergsen Catechismus - hetzij uit een boek van Ursinus hetzij uit een bundel van Lansberghius--wordt gelezen, gebeurt dit niet op grond van een persoonlijke instructie aan de zieketrooster, die er bij heeft voor te gaan, maar kragtens voorschrift van Heren XVII. Waarschijnlijk geldt hetzelfde wanneer de Kommandeur-na niet te hebben goedgevonden, dat de genoemde lekenpreeker, wanneer de scheepsbemanning en de passagiers aan wal zijn gegaan, des Zondags twee diensten houden zou (het volk moest gelegenheid krijgen om wat uit te spannen, het was de gehele week in touw!) - bijwoning van de ene dienst, die hij voldoende vond, verplicht stelde, op straffe van inhouding van het wijnrantsoen voor een week bij eerste overtreding: verbeurte 
van een maand gage bij de tweede en een jaar dwangarbeid wanneer het driemaal voorkwam.

Doch ook in verschillende gevallen, waarin Van Riebeeck niet in opdracht van zijn principalen, maar krachiens eigen initiatief handelde, is niet alles wat hij wilde en deed voor zijn levensopvatting representatief geweest. Zijn verlangen om uit Angola en Madagascar negers als werkkrachten ingevoerd te krijgen, zijn mobiliseren van de kolonie om op den Zondag na den kerkdienst een kolossale visvangst op touw te zetten en dergelijke. Dit laatste zal hij wel als ,een werk van noodzakelijkheid" beschouwd hebben, onvermijdelijk terwille van de voedselvoorziening, die wanneer de Hottentotten op een gegeven ogenblik niet met hun kudden in de nabije ongeving waren, al heel spoedig stagneerde; een werk van dien aard dus, dat ook de synodes in patria niet ongeoorloofd achtten. En wat die tewerkstelling van slaven betreft: had hij deze niet geoorloofd geacht, hij zou in zijn tijd zóó 'n witte raaf, zóó 'n uitzondering zijn geweest, dat hij door zijn medechristenen, in Nederland en elders algemeen voor een verminderd toerekeningsvatbare zonderling zou zijn aangerien.

Zijn er dan in het geheel wel uitingen en daden te noemen, waaruit ons iets omtrent een persoonlijke overtuiging blijkt? Niet zo vele, naar het mij voorkomt, maar geheel ontbreken doen zij toch niet.

Naar het mij voorkomt is voor de hand liggend in dezen meer op morele, dan op zuiver religieuze faktoren te letten. De bouwer van een volks- en staatsgemeenschap komt immers noodzakelijkerwijze meer met de handhaving der Tien Geboden, dan met de strijd voor de waarheid en de belijdenisschriften van de diverse delen van de Christelijke kerk, meer met etische dan met dogmatische aangelegenheden in aanraking. Welnu, op het genoemde gebied lijken mij o.a. de volgende factoren van betekenis te zijn geweest:

1) Als hij zijn kolonie van vrijburgers gaat stichten wil hij daarvoor geen mannen in aanmerking laten komen, die eerder in Batavia zijn geweest. Wie daarvandaan komt heeft doorgaans te veel met schraperijen en knoeierijen kennis gemaakt, dan dat men aan de Kaap niet voor een slechten invloed van zrjn kant te vreezen zou hebben. En Van Riebeeck wilde dit zoveel mogelijk vermijden. Zelfs was hij in verband met het drijven van particulieren handel eenmaal ter verantwoording geroepen: zijn daaruit gegroeide afkeer ervan was sedert blijkbaar hartgrondig geworden;

2) wanneer een vrij-houtzager zich als lid van de Burgerraad slecht gedraagt „met drincken, clincken, vechten, smijten en leelijk spreeken," 
in plaats van zijn medekolonisten ten voorbeeld te strekken, ontslaat hij hem; zoo wordt toch immers schade aan "de luyster des Raets" toegebracht, en

3) bii gelegenheid, dat een schepeling zich tijdens zijn verblijf aan de Kaap een zware straf op den hals had gehaald-om smaad van den kommandeur luidde de eis tegen hem: met een doorpriemde tong driemaal gekielhaald worden en, als hij daar levend afkwam tien jaar opsluiting op het Robbeneiland!-verminderde hij, de man tegen wie het misdrijf gericht was geweest, die straf tot ... niet meer dan degradatie tot trompetter!

Welnu, in deze zorg voor zuivere verhoudingen binnen den kring, waarvoor hij verantwoordelijk was-hoe klein die ook wezen mocht: inclusief honderd Compagnies ambtenaren, een drie honderd tachtig mensen omvattend!-in zijn waakzaamheid, uit het bovenstaande blijkend, dat op de regeerders van de kolonie niets te zeggen viel, en in zijn vrij-zijn van „eigensoeckelickheyt” en hogen dunk van zichzelf zie $\mathrm{ik}$ het karakteristieke van zijn persoon. En in den zo strevende-niet in het minst in de man, die de laatstgenoemde eigenschap vertoont-vinden wij immers den Calvinist; niet zoals hij altijd is, maar zoals hij krachtens zijn levensopvatting zich tenminste in zijn beste ogenblikken vertoont.

Van Riebeeck is zeker geen man van de postuur van Jan Pietersz. Coen geweest. Maar er behoeft dan ook nooit extra moeite gedaan te worden om voor zijn ereherstel te pleiten, zoals het voor dien grootste nodig bleek. Hij was een man, zoals men er ook heden Suid-Afrikaopdat de ontwikkeling van dat land voorspoedig zij-gaarne in steeds groter overvloed toewenst.

Aerdenhout 1) Nederland.

1) Toen Van Riebeeck voor het eerst de bossen achter de Tafelberg zag riepen deze hem aanstonds „den grote" (nog bestaande) „ende cleyne Houtte" (de andere, Aerden-hout) voor den geest. Daarom mocht een woord van hulde uit die streek bij zijn feest niet ontbreken.

DE SCHRIJVER. 